\title{
Espiritualidade, religiosidade e malformação congênita: uma revisão integrativa de literatura
}

\author{
Spirituality, religiosity and congenital malformation: an integrative literature review \\ Espiritualidad, religiosidad y malformación congénita: una revisión integradora de la literatura
}

\author{
Ana Cláudia Gomes Viana'; Maria Emília Limeira Lopes"; Mônica Ferreira de Vasconcelos"II; Carla Braz Evangelista"V; \\ Débora Rodrigues Alves de Limav ${ }^{\mathrm{V}}$ Adriana Marques Pereira de Melo Alves ${ }^{\mathrm{V}}$
}

\begin{abstract}
RESUMO
Objetivo: investigar a produção científica sobre a espiritualidade e religiosidade no contexto da malformação congênita. Método: revisão integrativa da literatura, sobre o tema, com busca realizada nas bases de dados Pubmed, Lilacs e Scielo, a qual incluiu artigos de 2007 a 2017. Resultados: foram examinadas 28 publicações, cujas análises textuais permitiram a construção de duas categorias: práticas espirituais e religiosas e o enfrentamento do diagnóstico e nascimento pelos familiares; espiritualidade, religiosidade e cuidado com a criança malformada. Conclusão: mesmo possuindo significados diferentes, os estudos revelaram que a espiritualidade em saúde é, com frequência, associada à religiosidade. Essa dimensão humana mostrou-se relevante diante do enfrentamento do diagnóstico de malformação congênita e serviu como fonte de sustento para o enfrentamento do cuidado com seus portadores.
\end{abstract}

Descritores: Espiritualidade; anormalidades congênitas; cuidadores; criança.

\section{ABSTRACT}

Objective: to investigate the scientific production about spirituality and religiosity in the context of congenital malformation. Method: this integrative literature review, conducted in the PubMed, LILACS and SciELO databases, included papers published from 2007 to 2017. Results: textual analysis of the 28 publications examined enabled two categories to be constructed: Spiritual and religious practices, and families' coping with the diagnosis and birth; and Spirituality, religiosity, and care for the malformed child. Conclusion: the studies, although having different meanings, have shown that spirituality in health is often associated with religiosity. This human dimension proved to be important in coping with the diagnosis of congenital malformation, and served as a source of support in dealing with the care for those affected.

Descriptors: Spirituality; congenital abnormalities; caregivers; child.

\section{RESUMEN}

Objetivo: investigar la producción científica sobre la espiritualidad y la religiosidad en el contexto de la malformación congénita. Método: revisión integradora de la literatura, sobre el tema, llevada a cabo en las bases de datos PubMed, LILACS y SciELO, que incluyó artículos de 2007 a 2017. Resultados: se examinaron 28 publicaciones, cuyos análisis textuales permitieron la construcción de dos categorías: prácticas espirituales y religiosas y el enfrentamiento del diagnóstico y del nacimiento por los familiares; espiritualidad, religiosidad y cuidado del niño malformado. Conclusión: incluso teniendo diferentes significados, los estudios revelaron que la espiritualidad en la salud se asocia, frecuentemente, con la religiosidad. Esta dimensión humana demostró ser relevante en el enfrentamiento del diagnóstico de la malformación congénita y sirvió como fuente de sustento para enfrentar las dificultades del cuidado de sus portadores.

Descriptores: Espiritualidad; anomalías congénitas; cuidadores; niño.

\section{INTRODUÇÃO}

A malformação congênita é entendida como toda anomalia de acometimento funcional ou estrutural que ocorre no desenvolvimento fetal, podendo acarretar defeitos anatômicos, funcionais ou estéticos que, conforme o nível de gravidade pode levar ao comprometimento significativo da qualidade de vida e até mesmo à morte ${ }^{1}$.

'Enfermeira. Especialista. Aluna Curso de Mestrado, Programa de Pós-Graduação em Enfermagem da Universidade Federal da Paraíba. Brasil. E-mail: anacviana2009@hotmail.com.

"Enfermeira. Doutora em Educação. Professora Adjunta, Universidade Federal da Paraíba. Brasil. E-mail: mlimeiralopes@yahoo.com.

I"Enfermeira. Mestre em Enfermagem. Aluna Curso de Doutorado. Programa de Pós-Graduação em Enfermagem da Universidade Federal da Paraíba. Brasil. E-mail: vaskoncelos.vaskoncelos@hotmail.com.

IVEnfermeira. Mestre em Enfermagem. Aluna do Curso de Doutorado, Programa de Pós-Graduação em Enfermagem da Universidade Federal da Paraíba. Brasil. E-mail: carlabrazevangelista@gmail.com.

vEnfermeira. Aluna do Curso de Mestrado. Programa de Pós-Graduação em Enfermagem da Universidade Federal da Paraíba. Brasil. E-mail: deboraufpbsud@gmail.com.

VIEnfermeira. Doutora em Enfermagem. Professora, Universidade Federal da Paraíba. Brasil. E-mail: ffadriana@ig.com.br. 
O avanço tecnológico ocorrido na área da saúde, em particular no âmbito da neopediatria, permitiu que a sobrevivência de crianças consideradas de alto risco, a exemplo das acometidas por malformações congênitas graves, se tornasse uma realidade na nossa sociedade ${ }^{2}$. Por conseguinte, essa evolução dos recursos utilizados na saúde resultou na exaltação do conhecimento científico em detrimento do humanístico, acarretando certo grau de esquecimento dos valores tidos como essenciais, tais como espiritualidade e religiosidade, para a oferta de um cuidado humanizado ${ }^{3}$.

Para os pais, o fato de o filho portar um agravo com implicação negativa à saúde tende a ocasionar forte impacto emocional, além de sentimentos como: medo, choque, negação e até mesmo a sensação de luto pela perda do filho idealizado ${ }^{4}$. Diante de tal impacto, é comum que os pais recorram aos aspectos espirituais na tentativa de encontrar um significado para a deformidade apresentada pela criança ${ }^{5}$.

A espiritualidade é entendida como a busca do sentido e do significado da vida, transcendendo o tangível e proporcionando o sentir humano à experiência de algo maior que a própria existência, sendo ou não relacionada com uma prática religiosa formal ${ }^{3}$. Trata-se de um aspecto que surge através das circunstâncias ocorridas no cotidiano, onde o homem, conforme sua visão de mundo, irá atribuir significado às histórias pessoais de vida de cada sujeito ${ }^{6}$.

A religiosidade está relacionada à crença do indivíduo acerca de uma determinada religião. Essa, por sua vez, vincula-se a uma doutrina pautada em rituais e crenças praticadas em busca de uma conexão com o Divino que pode ser Deus ${ }^{6}$.

A espiritualidade e a religiosidade vêm destacando-se no campo da saúde por representar fonte de força e de conforto perante as tribulações da vida, como no caso do enfrentamento de doenças. Assim sendo, o cuidado espiritual não deve ser negligenciado pelos profissionais da área da saúde, devendo ser ofertado sem haver emissão de julgamento nem imposição de religião ${ }^{7}$.

Todavia, percebe-se que, apesar da progressão do número de estudos a respeito da espiritualidade no âmbito da saúde, ainda é escassa a produção de pesquisas que abordem essa dimensão humana no tocante a malformação congênita. Nesse sentido, a espiritualidade precisa ser mais explorada, pois se destaca como recurso que pode subsidiar os familiares, principalmente os pais, no enfrentamento da situação, servindo também para nortear os profissionais da saúde para a prática assistencial nesse contexto.

Ante o exposto, este estudo teve como objetivo investigar a produção científica sobre a espiritualidade e religiosidade no contexto da malformação congênita.

\section{METOdOLOGIA}

Trata-se de revisão integrativa, método que permite, por meio da análise de pesquisas relevantes, a síntese do conhecimento acerca de um determinado assunto ${ }^{8}$. Para tal, foram percorridas, criteriosamente, as seguintes etapas: identificação do tema e da questão norteadora; estabelecimento dos critérios de inclusão e exclusão; extração das informações dos estudos selecionados; organização das informações em um banco de dados; análise e interpretação dos resultados obtidos e apresentação da revisão ${ }^{9}$.

A fim de possibilitar a busca nas bases de dados, foi elaborada a seguinte questão norteadora: qual a produção científica existente no cenário nacional e internacional acerca da espiritualidade no contexto da malformação congênita? Para tanto, foram utilizadas as seguintes bases de dados on-line: SciELO (Scientific Electronic Library Online), PubMed (U.S. National Library of Medicine), e LILACS (Literatura Latino-Americana e do Caribe em Ciências da Saúde).

A busca dos estudos se deu nos meses de junho a setembro de 2018, utilizando-se como estratégia de investigação os seguintes descritores: espiritualidade; anomalia congênita; família; criança. Todos foram indicados através dos Descritores em Ciências da Saúde (DeCSs) e pesquisados nos idiomas português, inglês e espanhol na SciELO e LILACS. Na PubMed, a pesquisa se deu através do Mesh (Medical Subject Heading) congenital anormalities; spirituality; religiosity. Para o cruzamento dos descritores foi utilizado o operador booleano AND.

Os critérios de inclusão estabelecidos foram: artigos escritos nos idiomas português, inglês e espanhol, disponíveis na íntegra online, publicados no recorte temporal de 2007 e 2017 e que abordassem a referida temática no título, resumo ou texto. Foram excluídos: artigos de revisão, dissertações, teses, cartas ao editor, editoriais, relato de experiência e artigos em duplicidade.

Para facilitar a análise dos resultados evidenciados, foram construídas figuras mostrando o fluxograma da seleção das obras, a apresentação da síntese de cada estudo, a qual descreve os itens título, ano, metodologia; e, e por último, a relação dos principais desfechos acerca da espiritualidade no contexto da malformação congênita. Os resultados foram analisados, interpretados e discutidos em duas categorias: Práticas espirituais e religiosas e o enfrentamento do diagnóstico e nascimento pelos familiares; e Espiritualidade, religiosidade e cuidado com a criança malformada. 
O fluxograma referente ao percurso adotado pelos pesquisadores para o levantamento bibliográfico e apresentado na Figura 1.
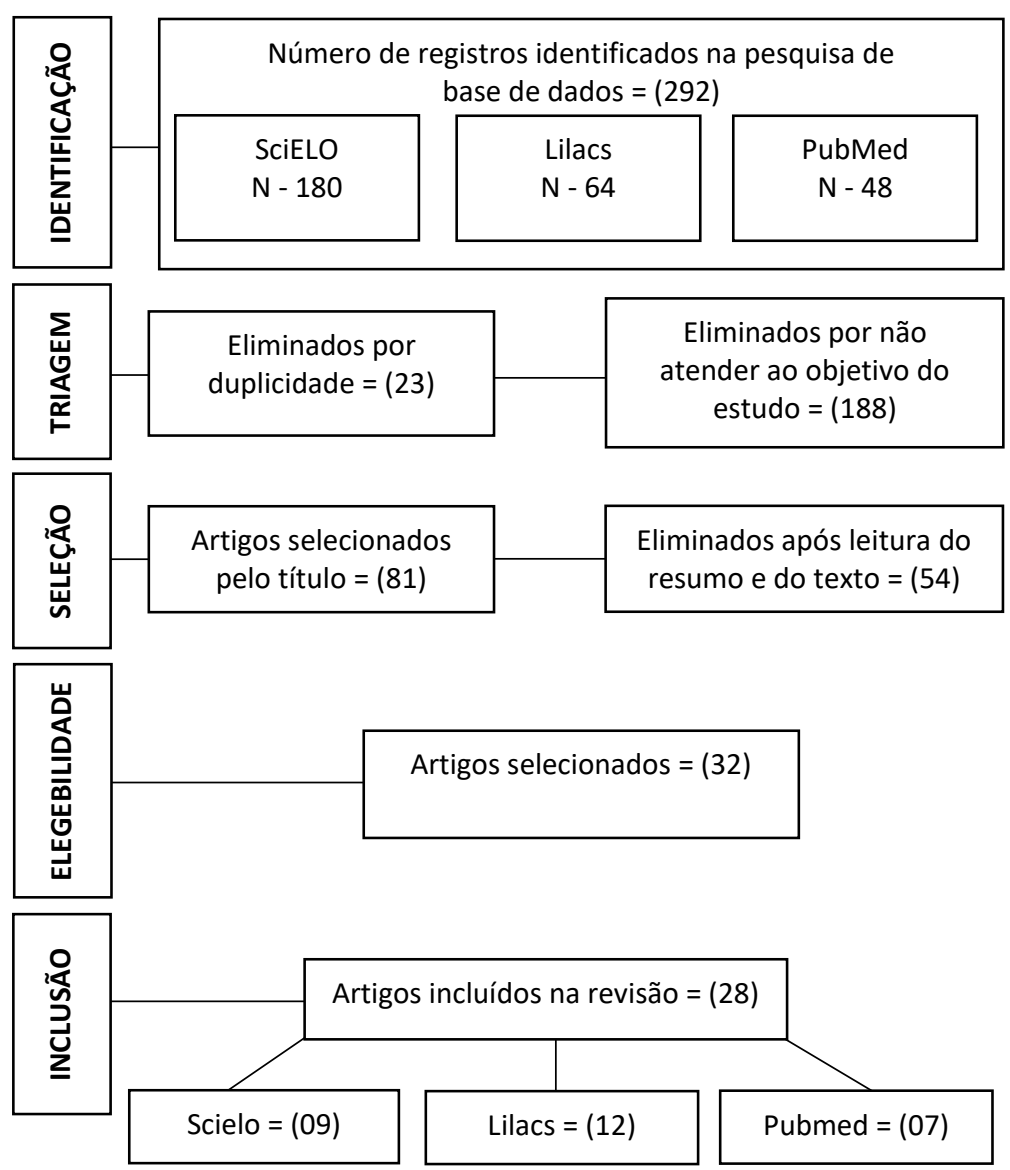

FIGURA 1: Fluxograma de sistematização da busca nas bases de dados Scielo, Lilacs, Pubmed, Redalyc João Pessoa, Brasil, 2018.

\section{RESULTADOS E DISCUSSÃo}

Foram analisados 28 artigos científicos ${ }^{20-37}$ pertinentes à temática investigada, dos quais, 20 (71,5\%) estão disponíveis no idioma português, $7(25 \%)$ em inglês e apenas $1(3,5 \%)$ em espanhol. A abordagem metodológica que prevaleceu foi a qualitativa - 20 (71,5\%), seguindo-se a quantiqualitativa - $4(14,2 \%)$, a quantitativa - $2(10,7 \%)$ e $1(3,6 \%)$ estudo de caso. Os anos que mais produziram foram 2011(21,4\%), 2012 (17,9\%), 2013 (14,3\%) e 2016 (14,3\%).

Do total da amostra, prevaleceram os estudos que trouxeram a temática espiritualidade/ religiosidade entre os familiares de crianças malformadas - 85,71\% (24) e apenas estudos 4 (14,28\%) trazem a espiritualidade/religiosidade no tocante à comunicação e ao cuidado desempenhado por profissionais da saúde com a criança malformada.

A distribuição completa do material empírico utilizado nesta revisão está especificada na Figura 2 e os principais desfechos de cada estudo estão apresentados na Figura 3.

As duas categorias resultantes desta revisão integrativa são analisadas a seguir:

\section{Práticas espirituais e religiosas e o enfrentamento do diagnóstico e nascimento pelos familiares}

A chegada de um filho com malformação congênita gera mudanças impactantes na dinâmica familiar e demanda ajustes para enfrentar uma nova situação. Sob esse aspecto, estudo aponta que o modo como o diagnóstico é informado aos pais pode interferir no processo de aceitação da criança por eles, sobretudo quando a comunicação é dada tardiamente ou por meio de informações incompletas e confusas ${ }^{14}$. 
Com base nos periódicos analisados, percebeu-se que as práticas espirituais e religiosas, por associarem-se aos sentimentos de esperança e de fé perante uma situação que demanda superação, aceitação e tomada de decisões complexas, podem se configurar em fonte de auxílio para os pais abalados pela descoberta da malformação congênita ${ }^{12,34,36}$.

Observou-se que tais práticas são frequentemente manifestadas pelos familiares por atitudes que expressam fé em Deus, oração, esperança de um milagre e sensação de tranquilidade, contribuindo assim para afastar o desespero diante do nascimento de uma criança acometida por um defeito genético ${ }^{32}$. Desse modo, é compreensível que os pais recorram a práticas espirituais como meio de sustentação para lidar com o diagnóstico da anomalia do filho ${ }^{13}$.

Sabe-se que a espiritualidade e religiosidade no campo da saúde influenciam o doente e seus familiares ${ }^{38}$. Nesse sentido, os sentimentos de fé e esperança obtidos através do suporte espiritual influíram, positivamente, no estado psíquico de mulheres grávidas de bebês malformados ${ }^{34}$, inclusive naquelas mulheres que já passaram pela experiência do luto relacionado com a perda fetal traumática, devido à anomalia em gestação anterior ${ }^{31}$.

Constatou-se que, apesar de a religiosidade ser apontada como uma prática compartilhada pela elevada adesão do público feminino ${ }^{12,13}$, os homens também buscam sustentação espiritual nas práticas religiosas, como forma de amenizar o sofrimento e na busca de encorajamento para lidar com eventos associados à condição do filho malformado ${ }^{11}$. É comum que os mesmos busquem orientação de um poder superior ${ }^{27}$. Para alguns deles, a fé se manifesta ao entregar-se o destino da criança nas mãos do Deus, o que confere conforto diante da situação vivida ${ }^{18}$.

\begin{tabular}{|c|c|c|}
\hline Título & Ano & Método \\
\hline Vivência de pais de crianças com cardiopatia congênita: sentimentos e obstáculos ${ }^{10}$ & 2016 & Qualitativo \\
\hline Enfrentamento do pai frente à malformação congênita do filho antes e depois do nascimento ${ }^{11}$ & 2016 & Quantiqualitativo \\
\hline Impacto emocional e enfrentamento materno da anomalia congênita de bebê na UTIN12 & 2016 & Quantiqualitativo \\
\hline Estresse, ansiedade, depressão e coping materno na anomalia congênita 13 & 2016 & Quantiqualitativo \\
\hline Experiências de médicos ao comunicarem o diagnóstico da deficiência de bebês aos pais ${ }^{14}$ & 2015 & Qualitativo \\
\hline $\begin{array}{l}\text { Pregnancy continuation and organizational religious activity following prenatal diagnosis of a lethal } \\
\text { fetal defect are associated with improved psychological outcome }{ }^{15}\end{array}$ & 2015 & Quantitativo \\
\hline Latino families with a child wite prader-willi syndrome: exploring needs for support ${ }^{16}$ & 2014 & Qualitativo \\
\hline Cuidado da criança com anomalia congênita: a experiência da família ${ }^{17}$ & 2013 & Qualitativo \\
\hline Pais de bebês malformados: um enfoque vivencial ${ }^{18}$ & 2013 & Qualitativo \\
\hline Perda e luto: vivência de mulheres que interrompem a gestação por malformação fetal letal ${ }^{19}$ & 2013 & Qualitativo \\
\hline Crianças portadoras de hidrocefalia: dificuldades e vivência das mães ${ }^{20}$ & 2013 & Qualitativo \\
\hline O cuidado ao neonato com anomalia congênita: estratégia de enfrentamento de enfermeiros ${ }^{21}$ & 2012 & Qualitativo \\
\hline Crianças com necessidades especiais de saúde: cuidado familiar na preservação da vida ${ }^{22}$ & 2012 & Qualitativo \\
\hline $\begin{array}{l}\text { A concepção da família e religiosidade presente nos discursos produzidos por profissionais médicos } \\
\text { acerca de crianças com doenças genéticas }{ }^{23}\end{array}$ & 2012 & Qualitativo \\
\hline $\begin{array}{l}\text { It's not what you were expecting, but it's still a beautiful journey: the experience of mothers of } \\
\text { children with Down Syndrome }{ }^{24}\end{array}$ & 2012 & Qualitativo \\
\hline Estomas em neonatologia: um resgate da memória materna ${ }^{25}$ & 2012 & Qualitativo \\
\hline A experiência da doença na fibrose cística: caminhos para o cuidado integral ${ }^{26}$ & 2011 & Estudo de caso \\
\hline Spiritual needs of couples facing pregmancy termination because of fetal anomalies ${ }^{27}$ & 2011 & Qualitativo \\
\hline Sentimento de mulheres mãe diante da cirurgia neonatal nas malformações congênitas ${ }^{28}$ & 2011 & Qualitativo \\
\hline $\begin{array}{l}\text { Percepción de la calidad de vida de cuidadores de niños con cardiopatía congénita Cartagena, } \\
\text { Colombia }{ }^{29}\end{array}$ & 2011 & Quantitativo \\
\hline Pediatric cardiac surgery under the parents view: a qualitative study ${ }^{30}$ & 2011 & Qualitativo \\
\hline $\begin{array}{l}\text { Religiosity is an important part of coping with grief in pregnancy after a traumatic second trimester } \\
\text { loss }^{31}\end{array}$ & 2011 & Quantitqualitativo \\
\hline Avaliação das famílias de crianças com cardiopatia congênita e a intervenção de enfermagem ${ }^{32}$ & 2010 & Qualitativo \\
\hline $\begin{array}{l}\text { O sofrimento amenizado com o tempo: a experiência da família no cuidado da criança com } \\
\text { anomalia congênita }{ }^{33}\end{array}$ & 2009 & Qualitativo \\
\hline $\begin{array}{l}\text { O impacto da malformação fetal: indicadores afetivos e estratégias de enfrentamento da } \\
\text { gestante }^{34}\end{array}$ & 2009 & Quantitativo \\
\hline Percepção da família que vivencia o cuidado da criança com mielomeningocele: estudo descritivo ${ }^{35}$ & 2009 & Qualitativo \\
\hline $\begin{array}{l}\text { Values parents apply to decision-making regarding delivery room resuscitation for high-risk } \\
\text { newborns }{ }^{36}\end{array}$ & 2008 & Qualitativo \\
\hline Os profissionais de enfermagem diante do nascimento da criança com malformação congênita ${ }^{37}$ & 2007 & Qualitativo \\
\hline
\end{tabular}


A espiritualidade se destacou como fator significativo no enfrentamento da malformação, manifestada através da fé na cura e/ou na recuperação do filho cardiopata ${ }^{10}$.

A religião foi apontada como segunda estratégia de enfrentamento usada pelos pais, GR $(3,92)$; GA $(3,78)$, demonstrando que a forma dos homens enfrentarem a situação é semelhante à da companheira ${ }^{11}$.

A religião foi o modo de enfrentamento mais utilizado (escore de 4,14) com 0,64 acima da média padrão indicando elevada busca da religiosidade no enfrentamento de eventos estressores em saúde ${ }^{12}$.

A busca da prática religiosa foi apontada como a estratégia de enfrentamento mais utilizada pelas participantes, até mesmo pelas mães que relataram não pertencer a nenhum segmento religioso formal ${ }^{13}$.

Foram sinalizadas abordagens inadequadas e ineficazes, o despreparo e dificuldades na comunicação da notícia, associados à falta de formação acadêmica para desempenhar esta tarefa ${ }^{14}$.

O grupo que optou pela interrupção da gravidez relatou maior nível de desespero $(p=0,02)$, evitação $(p=0,008)$ e depressão $(p=0,04)$ em relação ao que optou pela continuação da gestação. Em ambos os grupos atividade religiosa organizacional associouse a uma redução do luto ${ }^{15}$.

A espiritualidade emergiu através das falas das mães como menção ao aspecto religioso. A fé é referida como uma maneira de lidar e aceitar os desafios diários ${ }^{16}$.

Os familiares recorrem à religião em busca de amparo para prosseguirem na trajetória de cuidar da criança e em busca de respostas para os questionamentos sobre a razão da vinda dessa criança ${ }^{17}$

Os pais buscaram apoio espiritual através da crença em Deus ao entregarem o destino da criança nas mãos dele. A fé foi apontada como forma de se conformar com a situação do filho ${ }^{18}$.

Durante a busca de explicações, algumas mulheres se pautaram na religião e na crença ao apontar Deus como responsável pela malformação, podendo aceitar e conformar-se ou associar a um castigo ${ }^{19}$

A espiritualidade auxilia no enfrentamento das adversidades. As depoentes demonstraram conformismo ao associar o cuidado dispensado ao filho como uma missão determinada por um Ser maior ${ }^{20}$

As estratégias de enfrentamento mais utilizadas foram a focalizada no problema e focalizada nas emoções, ambas demonstradas, entre outros aspectos, pelas conviç̧ões religiosas ${ }^{21}$.

Os familiares buscam amparo na religiosidade e na espiritualidade. Tida como rede de apoio o suporte espiritual serve para que eles continuem acreditando na recuperação da criança22.

Identificaram-se quatro tradições culturais muito presentes ao discurso médico: a norma, a razão, a família e a religiosidade judaico-cristã23.

Tanto a espiritualidade como a religião organizada se mostraram úteis à mediação do estresse e ao apoio das mães de filhos com Sindrome de Down, como também ao crescimento pessoal delas ${ }^{24}$.

A mãe recorre à religião para dar sentido e enfrentar o fato de ter um bebê que necessita usar estoma ${ }^{25}$

Houve reconhecimento da esfera religiosa e espiritual no planejamento dos cuidados. Tais elementos foram citados como suportes desde o diagnóstico até a projeção futura de crianças com anomalia ${ }^{26}$.

A principal necessidade identificada nos pais foi orientação de um poder superior e alguém para orar por eles. Os pais não desejavam que a equipe de saúde discutisse sua fé e nem orassem com eles ${ }^{27}$.

Os profissionais da saúde, além da destreza tecnocientífica, devem possuir sensibilidade e percepção para intervir na dimensão biopsicossocial e espiritual da criança de seus familiares, sobretudo na da mãe ${ }^{28}$

Entre os cuidadores $(84,8 \%)$ apontam o bem-estar espiritual como o componente mais afetado, interferindo na qualidade de vida deles $^{29}$.

Mães de filhos cardiopatas disseram também utilizar a religião, dentre outros aspectos, como rede de apoio, parecendo contribuir com um comportamento resiliente ${ }^{30}$.

A religiosidade foi apontada como um importante recurso no enfrentamento do luto entre mulheres grávidas que sofreram perdas de gestações anteriores por malformação fetal ${ }^{31}$.

Independente do seguimento religioso, a religião associada à crença em Deus se configurou em um auxílio no enfrentamento da enfermidade, por meio da oração, força, fé32.

A espiritualidade e religiosidade, através da confiança em Deus, confere conforto e força à família ${ }^{33}$.

Dentre às participantes, 12 (54,5\%) delas utilizam como estratégia de enfrentamento a busca de práticas religiosas por englobarem os sentimentos de esperança e de fé diante o diagnóstico de malformação fetal ${ }^{34}$.

A espiritualidade foi mencionada como fonte de sustentação para lidar com a doença do filho ${ }^{35}$.

Religião, espiritualidade e esperança serviram para auxiliar os pais na tomada de decisão quanto à ressuscitação do filho com malformação grave na sala de parto ${ }^{36}$.

A busca do Ser Supremo e da fé foi pontuada como meio para superação das adversidades surgidas na prática profissional associada ao cuidado ofertado à criança malformada ${ }^{37}$.

FIGURA 3: Principais desfechos trazidos pelos periódicos incluídos na revisão integrativa, publicados de 2007 a 2017. João Pessoa, Brasil, 2018

Diante do impacto causado pela descoberta, é comum que os pais passem por um processo de ajustamento ante a nova realidade, onde quanto mais diferente a criança for daquela almejada anteriormente ao diagnóstico, mais difícil será a adaptação ao seu nascimento ${ }^{33,34}$. Este fato corrobora o resultado de pesquisa que aponta a vivência de luto 
diante da não concretização do filho esperado e ainda certo grau de rejeição da criança malformada, alegando os pais não merecerem tal fardo ${ }^{17}$.

Ainda em relação ao processo de luto, pesquisa reconhece que a prática de atividade religiosa configurou-se em meio para reduzi-lo entre os que vivenciaram a perda concreta do filho, por interrupção da gravidez, com autorização judicial, bem como entre os que levaram a gestação adiante mesmo sabendo que o filho iria morrer após o nascimento por portar um defeito congênito letal ${ }^{15}$.

Destaca-se ainda que a espiritualidade fornece força para prosseguir nessa difícil jornada, podendo também influenciar nas conclusões obtidas acerca do problema. Nesse sentido, muitas mães se pautam em explicações religiosas ao tentar dar significado à experiência de ter um filho que não condiz com o planejado durante a gravidez ${ }^{25,26}$. Através da confiança em Deus os familiares de crianças especiais dizem encontrar conforto e esperança diante do ocorrido ${ }^{33}$.

Apesar de a espiritualidade/religiosidade ser apontada por diversos estudos como prática usada para a superação dos sentimentos negativos associados à descoberta da anomalia, pesquisa indica que a manifestação da espiritualidade, quando atrelada a convicções religiosas, fez com que alguns pais atribuíssem a malformação do filho a uma espécie de castigo ou punição divina, intensificando a sensação de culpa associada à condição da criança ${ }^{19}$.

Ainda que o diagnóstico inicial provoque certa inquietude e raiva contra Deus, despertando vários questionamentos sobre o porquê de ter um filho com anomalia, com o passar do tempo as experiências espirituais podem favorecer a superação das inquietudes preambulares, conforme foi relatado por mães de filhos com Síndrome de Down ${ }^{24}$. É notório que diante de situações onde a inexistência de cura é uma realidade, a busca da Divindade parece dar sentido a algo que, de início, parece inaceitável.

Apesar dos avanços nas pesquisas acerca da espiritualidade no contexto da saúde e da doença, os estudos atuais referentes a tais necessidades, em sua grande maioria, direcionam a temática para o contexto da finitude de indivíduos com idade avançada ou para o âmbito oncológico ${ }^{39}$. Entretanto, casais que enfrentam situações como a infertilidade, uma gravidez complicada ou a perda da criança antes ou depois do nascimento também compactuam das mesmas necessidades, no tocante à espiritualidade tida como componente do cuidado, requerendo dos pesquisadores o despertar para a realização de estudos específicos para essa problemática ${ }^{31}$.

Mediante os estudos analisados, a espiritualidade/religiosidade mostrou-se servir como fonte de sustentação para os pais abalados pelo diagnóstico e nascimento de um filho com malformação congênita por subsidiá-los na busca de significados, como também na tomada de decisão perante um evento complexo e não planejado. Todavia, percebe-se haver necessidade de maior exploração da temática, a fim de aperfeiçoar a prática destinada ao conforto espiritual desses indivíduos.

Ante o exposto, ressalta-se que o suporte espiritual/religioso não pode ser ignorado durante o cuidado ofertado pelos profissionais de saúde aos familiares de crianças malformadas.

\section{Espiritualidade, religiosidade e cuidado com a criança malformada}

O pós-parto é o momento em que a mãe irá de fato conhecer as limitações do filho malformado, o que pode gerar estresse, ansiedade e até depressão. Tais sentimentos podem ser intensificados com a necessidade de internação do bebê em unidade de terapia intensiva neonata $\left.\right|^{13}$. Nesse período, os pais irão, de fato, lidar com um modo de cuidar diferente do convencional, o que pode ser considerado um desafio, visto que, com a ida para casa, eles terão que se responsabilizar pela assistência prestada ao filho ${ }^{21}$.

É explícito que o avanço tecnológico permite que muitas dessas crianças se beneficiem de avançadas técnicas cirúrgicas para reparação de dano proveniente da anomalia ${ }^{2}$. Porém, a necessidade de procedimentos complexos, a exemplo de uma intervenção cirúrgica, representa para os pais um evento que se associa ao medo de o filho morrer, à culpa, impotência, angústia e ansiedade ${ }^{30}$.

É pertinente destacar que, em algumas circunstâncias, as intervenções cirúrgicas resultam na colocação de dispositivos que requerem dos pais aprendizado para lidar com um modo de cuidado diferente do convencional, como no caso de crianças colostomizadas. Doutra parte, estudo demonstra que mães tendem a recorrer a Deus à busca de força para encarar a história vivenciada ${ }^{10,16,25}$.

Sabe-se que cuidar de uma criança com anomalia congênita é uma prática inicialmente difícil, envolta por períodos de desequilíbrio e de enfrentamento de dificuldades. Nesse sentido, estudos comprovam que o suporte espiritual/religioso permanece como rede de apoio significativa, fortalecendo os familiares, principalmente os pais, que são cuidadores principais, na trajetória de cuidar do filho malformado ${ }^{17,33}$. Constata-se que a relação que esses cuidadores estabelecem com o Divino contribui para que a fé e a esperança na recuperação e, inclusive, na cura sejam mantidas ${ }^{10,22}$, até mesmo quando a medicina nega a possibilidade de cura ${ }^{4}$. 
A espiritualidade é uma experiência única percebida de modo individualizado, podendo ser influenciada pelas crenças pessoais $^{6}$. Ao expressarem a compreensão de espiritualidade, mães de crianças com Síndrome de Down relacionaram essa dimensão humana com um profundo estado de conexão com um ser superior ou com Deus, e demonstraram reconhecer esse elemento como fonte de apoio diante da experiência de ser mãe de um filho sindrômico ${ }^{24}$.

Ao dedicar-se, incondicionalmente, aos cuidados com o filho, a mãe, na condição de cuidadora principal, torna-se vulnerável à sobrecarga física e emocional ${ }^{20}$. É comum que a autorrealização de atividades cotidianas básicas, como dormir e repousar, fiquem prejudicadas, interferindo na sua qualidade de vida. Daí a ânsia dessas mulheres por buscar sustentação em algo transcendente e espiritual que as auxiliem a encontrar a paz desejada ${ }^{4,35}$.

Apesar de as pesquisas ressaltarem a importância que a espiritualidade exerce nesse contexto, constata-se que o componente espiritual de cuidadores de crianças cardiopatas é bastante afetado (84,8\%), o que impacta negativamente na qualidade de vida desses indivíduos ${ }^{29}$. Porém, mesmo diante do estresse gerado pela sobrecarga, essas mulheres se pautam nas convicções espirituais para aceitar a tarefa de cuidar como uma missão e acreditam não lhes caber qualquer tipo de questionamento acerca da malformação portada pela criança ${ }^{20}$. A respeito disso as mães de crianças com Síndrome de Prader Willi acreditam que os filhos são tidos como anjos enviados por Deus com algum propósito, refletindo o papel que a espiritualidade representa diante de um cenário onde é preciso aceitar e lidar com os desafios diários de cuidar de um filho com necessidades especiais de saúde ${ }^{16}$.

É notório que o cuidado cotidiano de um filho com necessidade especial de saúde requer dos pais, principalmente da mãe, esforços para suprir todas as demandas impostas conforme a necessidade apresentada, tais como: realização de procedimentos complexos (por exemplo: aspiração de via aérea, administração de dieta por sonda; acompanhamento da criança durante consultas médicas, fisioterapias, dentre outros). Mediante todas essas demandas, é inegável que, colocando o controle da circunstância vivida sob a incumbência de Deus, esses cuidadores, mesmo não se eximindo totalmente do desgaste natural nesse processo, podem encontrar razão e força para se manterem firmes na trajetória do cuidar.

Entre os profissionais da saúde, os estudos demonstraram que práticas espirituais e crenças religiosas influenciam no modo com que à anomalia é percebida por eles e como se sentem em relação à missão de cuidar ${ }^{21,22}$. Sob esse aspecto, alguns enfermeiros descrevem desconforto ao lidar, profissionalmente, com o diferente e com os limites da vida, resultando isto em sofrimento para esses profissionais, sendo a religiosidade mencionada como um meio para buscar conforto e superação das adversidades associadas ao cotidiano do cuidado com essas crianças ${ }^{37}$.

Embora sejam conceitos diferentes, nota-se que, na prática, é comum a compreensão da religião/espiritualidade como indissociáveis. Todavia, é importante que profissionais da saúde intervenham na dimensão espiritual do paciente e de seus familiares com o imenso respeito à sua cultura e à religião ${ }^{28,38}$.

Entre alguns profissionais médicos, o fato de desempenhar uma árdua tarefa de cuidar de uma criança malformada é tido como meio para o alcance da salvação após a morte, crença essa pautada na doutrina cristã. Tais profissionais, durante a participação de uma pesquisa, expressaram a crença de que tanto as mães como eles próprios, pelo fato de se dedicarem com amor a uma criança extremamente incapacitada, terão um bom lugar reservado após a morte ${ }^{23}$.

É sabido ainda que o apego à religião também pode se configurar em um fator de risco para a instauração de um estado de alienação ante as reais possibilidades de cura, o que pode desencadear a tomada de decisão e a criação de expectativas que não condizem com a gravidade do problema apresentado pela criança malformada ${ }^{13}$.

É valido salientar que a realização de novas pesquisas que aprimorem a compreensão da espiritualidade no contexto da malformação congênita muito tem a contribuir, pois pode servir para ampliar o conhecimento dos profissionais de saúde a respeito desse elemento humano como fonte de força, esperança e superação diante de situações difíceis, bem como para que a prestação da assistência às crianças e seus pais aconteça sob a perspectiva da integralidade, de modo que as dimensões que transcendem o corpo físico também sejam consideradas.

\section{CONCLUSÃO}

Ao analisar a produção científica sobre espiritualidade e malformação congênita constatou-se que, mesmo tendo significados diferentes, muitos estudos abordam a temática associada à religiosidade. Os resultados analisados reconhecem a importância que a espiritualidade tem no contexto da malformação congênita, seja diante da descoberta do diagnóstico, seja no processo de cuidar realizado principalmente pelos pais, mas também pelos profissionais de saúde e pelos demais membros familiares. 
Notou-se carência de estudos desenvolvidos com profissionais de saúde que abordem a espiritualidade, em especial no âmbito da malformação congênita, visto que dos periódicos que compuseram a amostra, apenas quatro trouxeram resultados obtidos por tais profissionais.

\section{REFERÊNCIAS}

1. World Health Organization. [Site de internet] Congenital anomalies. Fact sheet $n^{\circ} 370$. Updated January 2014. [cited 2018 May 9] Available from: http://www.who.int/mediacentre/factsheets/fs370/en/.

2. Cardoso MVLM, Lima VRM, Fontoura FC, Rodrigues SE, Saraiva IA, Fontenele FC. Therapies for neonates with congenital malformations admitted to a neonatal unit. Rev. eletrônica enferm. [Internet] 2015 [cited 2018 May 29]; 17(1): 60-8. DOI: https://doi.org/10.5216/ree.v17i1.22986.

3. Garanito MP, Cury MRG. Spirituality in pediatric practice. Rev. bioét. [Internet], 2016 [cited 2018 May 29]; 24(1): 49-53. DOI: http://dx.doi.org/10.1590/1983-80422016241105.

4. Colesante MFL, Gomes IP, Morais JD, Collet N. Impact on mothers' lives of caring for children with chronic illnesses. Rev. enferm. UERJ [Internet], 2015 [cited 2018 May 29]; 23(4): 501-6. DOI: https://doi.org/10.12957/reuerj.2015.4966.

5. Costa ES, Bonfim EG, Magalhães RLB, Viana LMM. Mothers' experiences of children with microcephaly. Rev. Rene (Online). [Internet], 2018 [cited 2019 Feb 11]; 19:e3453. DOI: http://dx.doi.org/10.15253/2175-6783.2018193453.

6. Rocha RCNP, Pereira ER, Silva RMCRA. The spiritual dimension and the meaning of life nursing care: phenomenologica approach. REME rev. min. enferm. [Internet], 2018 [cited 2019 Feb 11]; 22:e-1151. DOI: http://www.dx.doi.org/10.5935/14152762.20180082.

7. Araújo MAM, Batista RA, Silva Júnior IA, Sampaio CL, Martins LGF, Guerra DR et al. A percepção dos enfermeiros acerca dos cuidados espirituais. Logos \& Existência [Internet], 2015 [cited 2019 Feb 11]; 4(1): 84-94. Available from: http://www.periodicos.ufpb.br/ojs2/index.php/le/article/view/22671/13063.

8. Ercpe FF, Melo LS, Alcoforado CLGC. Integrative review versus systematic review. REME rev. min. enferm. [Internet], 2014 [cited 2019 Feb 11]; 18(1): 09-11. DOI: http://www.dx.doi.org/10.5935/1415-2762.20140001.

9. Botelho LLR, Cunha CCA, Macedo M. O método da revisão integrativa nos estudos organizacionais. Gestão e Sociedade [Internet], 2011 [cited 2018 Oct 10]; 5(11): 121-36. DOI: https://doi.org/10.21171/ges.v5i11.1220.

10. Mombach TSB, Sakamoto VTM, Magagnin JS, Coelho DF, Waterkemper R, Canabarro ST. Experience of parents of children with congenital heart disease: feelings and obstacles. Rev. Rene (Online). [Internet], 2016 [cited 2018 June 12]; 17(1): 128-36. DOI: http://dx.doi.org/10.15253/2175-6783.2016000100017.

11. Silva EHP, Girão ERC, Cunha ACB. Father coping face to the congenital malformation of son before and after the birth. Estud. pesqui. psicol. [Internet] 2016 [cited 2018 June 12]; 16(1):180-99. Available from: http://pepsic.bvsalud.org/pdf/epp/v16n1/v16n1a11.pdf.

12. Vicente SR, Paula KMP, Lopes AM, Muniz SA, Mancini CN, Trindade ZA. Emotional impact and maternal coping of congenital anomaly of babies in the nic. Psicol. saúde doenças. [Internet] 2016 [cited 2018 June 23]; 17(3): 454-67. DOI: http://dx.doi.org/10.15309/16psd170312.

13. Vicente SRCRM, Paula KMP, Silva FF, Mancini CN, Muniz SA. Estresse, ansiedade, depressão e coping materno na anomalia congênita. Estud. psicol. [Internet] 2016 [cited 2018 June 23]; 21(2): 104-16. DOI: http://dx.doi.org/10.5935/16784669.20160011.

14. Luisa V, Fiamengh GA, Carvalho SG, Madeira EAA, Assis SMB. Physicians' experiences when communicating the diagnosis of infants' disability to parents. Ciênc. Saúde. [Internet] 2015 [cited 2018 June 23]; 8(3): 121-28. DOI: http://dx.doi.org/10.15448/1983-652X.2015.3.21769.

15. Cope H, Garrett ME, Gregory S, Koch AA. Pregnancy continuation and organizational religious activity following prenatal diagnosis of a lethal fetal defect are associated with improved psychological outcome. Prenat. diagn. [Internet] 2015 [cited 2018 June 23]; 35(8): 761-68. DOI: https://doi.org/10.1002/pd.4603.

16. Chaij C, Han M, Graziano L. Latino families with a child with Prader-Willi syndrome: exploring needs for support. J. Soc. Work. Disabil. Rehabil. [Internet] 2014 [cited 2018 June 23]; 13(3): 207-25. DOI: http://dx.doi.org/10.1080/1536710X.2014.912184.

17. Bolla BA, Fulconi SN, Baltor MRR, Dupas G. Caring for a child with congenital anomalies: the experience of the Family. Esc. Anna Nery Rev. Enferm. [Internet], 2013 [cited 2018 June 29]; 17(2): 284-90. DOI: http://dx.doi.org/10.1590/S141481452013000200012.

18. Silva LLT, Madeira AMF, Oliveira CG, Lima SCS, Campos TMF. Pais de bebê malformado: um enfoque vivencial. Rev. enferm. Cent.-Oeste Min. [Internet] 2013 [cited 2018 June 29]. 3(3):770-9. DOI: http://dx.doi.org/10.19175/recom.v0i0.408.

19. Consonni EB, Petean EBL. Loss and grieving: the experiences of women who terminate a pregnancy due to lethal fetal malformations. Ciênc. saúde coletiva (Online), 2013 [cited 2018 June 29]; 18(9): 2663-670. DOI: http://dx.doi.org/10.1590/S1413-81232013000900021.

20. Costa ECL, Veloso RA, Feitosa JJM. Children with hhydrocephalus: difficulties and mothers experience. R. Interd. [Internet] 2013 [cited 2018 June 29]; 6(1): 71-79. Available from: https://revistainterdisciplinar.uninovafapi.edu.br/index.php/revinter/article/view/17/pdf_9.

21. Melo MM, Pacheco STA. Care of the newborn with congenital anomalies: coping strategies of nurses. Rev. pesqui. cuid. fundam. (Online). 2012 [cited 2018 June 29]; 4(3): 2636-44. Available from: http://www.seer.unirio.br/index.php/cuidadofundamental/article/view/1837/pdf_604. 
22. Silveira A, Neves ET. Crianças com necessidades especiais em saúde: cuidado familiar na preservação da vida. Cienc. cuid. Saúde. [Internet] 2012 [cited 2018 June 29]; 11(1):074-80. DOI: http://dx.doi.org/10.4025/cienccuidsaude.v11i1.18861.

23. Martins AJ, Cardoso MHCA, Llerena Júnior JC, Moreira MCN. Family and religious traditions present in medical discourses by medical professionals about children with genetic diseases. Ciênc. saúde coletiva (Online). 2012 [cited 2018 June 29]; 17(2): 545-53. DOI: http://dx.doi.org/10.1590/S1413-81232012000200027.

24. Pillay D, Girdler S, Collins M, Leonard H. It's not what you were expecting, but it's still a beautiful journey: the experience of mothers of children with Down syndrome. Disabil. Rehabil. [Internet] 2012 [cited 2018 June 29]; 34(18): 1501-10. DOI: https://doi.org/10.3109/09638288.2011.650313.

25. Cruz AC, Angelo M. Stomas in neonatology: recovering the mother's memory. Esc. Enferm. USP. [Internet] 2012 [cited 2018 June 29]; 46(6):1306-12. DOI: http://dx.doi.org/10.1590/S0080-62342012000600004.

26. Pizzignacco TP, Mello DF, Lima RG. The experience of disease in cystic fibrosis: the paths to comprehensive care. Esc. Enferm. USP. [Internet] 2011 [cited 2018 June 29]; 45(3): 638-44. DOI: http://dx.doi.org/10.1590/S0080-62342011000300013.

27. Cowchock FS, Meador KG, Floyd SE, Swamy GK. Spiritual needs of couples facing pregnancy termination because of fetal anomalies. J Pastoral Care Counsel. [Internet] 2011 [cited 2018 June 19]; 65(1): 1-10. DOI: https://doi.org/10.1177/154230501106500204.

28. Reis AT, Santos RS. The feelings of women-mothers faced with the surgery in newborn birth defects. Esc. Anna Nery Rev. Enferm. [Internet] 2011 [cited 2018 Apr 18];15(3): 490-96. DOI: http://dx.doi.org/10.1590/S1414-81452011000300007.

29. Pietro AM, Massa ER, Torres IE. Percepción de la calidad de vida de cuidadores de niños con cardiopatía congénita Cartagena, Colombia. Invest. educ. enferm. [Internet] 2011 [cited 2018 Apr 18]; 29(1): 9-18. Available from: http://www.scielo.org.co/pdf/iee/v29n1/v29n1a02.pdf.

30. Salgado CL, Lamy ZC, Nina RVAH, Melo LA, Lamy Filho F, Nina VJS. Pediatric cardiac surgery under the parents view: a qualitative study. Rev. bras. bir. cardiovasc. [Internet] 2011 [cited 2018 Apr 18]; 26(1): 36-42. DOI: http://dx.doi.org/10.1590/S0102-76382011000100009.

31. Cowchock FS, Ellestad SE, Meador KG, Koenig HG, Hooten EG, Swamy GK. Religiosity is an important part of coping with grief in pregnancy after a traumatic second trimester loss. J relig. health [Internet] 2011 [cited 2018 Apr 18]; 50(4):901-10. DOI: https://doi.org/10.1007/s10943-011-9528-y.

32. Meireles GS, Pellon LHC, Barreiro Filho RD. Avaliação das famílias de crianças com cardiopatia congênita e a intervenção de enfermagem. Rev. pesqui. cuid. fundam. (Online) 2010 [cited 2018 Apr 22]; 2(Ed.Supl):1048-56. DOI: http://dx.doi.org/10.9789/2175-5361.2010.v0i0.\%25p.

33. Guiller CA, Dupas GC, Pettengill MAM. Suffering eases over time: the experience of families in the care of children with congenital anomalies. Rev. latinoam. enferm. (Online). [Internet] 2009 [cited 2018 Apr 22];17(4): 495-500. DOI: http://dx.doi.org/10.1590/S0104-11692009000400010.

34. Vasconcelos L, Petean EBL. The impact of fetal malformation: pregnant women affective gauges and coping strategies. Psicol. saúde doenças. [Internet] 2009 [cited 2018 Apr 22]; 10(1): 69-82. Available from: http://www.scielo.mec.pt/pdf/psd/v10n1/v10n1a06.pdf.

35. Cipriano MAB, Lélis ALPA, Cardoso MVLML, Queiroz MVO. Perception of the family that existence the care of child with meningomyelocele: descriptive study. Online braz. j. nurs. (Online). 2009 [cited 2018 Apr 22]; 8(3). DOI: https://doi.org/10.5935/1676-4285.20092630.

36. Boss RD, Hutton N, Sulpar LJ, West AM, Donohue PK. Values parents apply to decision-making regarding delivery room resuscitation for high-risk newborns. Pediatrics. [Internet] 2008 [cited 2018 June 22]; 122(3): 583-9. Available from: https://www.ncbi.nlm.nih.gov/pubmed/18762529.

37. Dias IMAV, Santos IMS. Nursing Professionals Before of the Birth of a Child with Congenital Malformation. Esc. Anna Nery Rev. Enferm. [Internet] 2007 [cited 2018 June 22]; 11(1): 73-9. DOI: http://dx.doi.org/10.1590/S1414-81452007000100011.

38. Evangelista CB, Lopes MEL, Costa SFG, Batista PSS, Batista JBV, Oliveira AMM. Palliative care and spirituality: an integrative literature review. Rev. bras. enferm. (Online) 2016 [cited 2018 June 22]; 69(3):554-63. DOI: http://dx.doi.org/10.1590/00347167.2016690324i.

39. Arrieira ICD, Thofehrn MB, Porto AR, Moura PMM, Martins CL, Jacondino MB. Spirituality in palliative care: experiences of an interdisciplinary team. Esc. Enferm. USP. [Internet] 2018 [cited 2018 Oct 02]; 52:e03312. DOI: http://dx.doi.org/10.1590/S1980$220 \times 2017007403312$ 